Core Judgments of Instructional Designers in Practice 


\begin{abstract}
The tacit beliefs that affect all the judgments made during design (core judgments) of eleven practicing instructional designers were studied via their discussions of strong and weak designs during interviews. Transcripts were analyzed from a phenomenological perspective. The study demonstrates that, while designer judgment is rarely discussed in the field, these designers do appear to bring core judgments to bear on their designing and these judgments are complex in nature. Researchers argue that core judgment, unaccounted for in rational models of instructional design, requires further attention from scholars and design educators.
\end{abstract}




\section{Core Judgments of Instructional Designers in Practice}

\section{Introduction}

Instructional designers carry out "the practice of facilitating learning and improving performance by creating, using, and managing appropriate technological processes and resources" (Januszewski \& Molenda, 2007). Scholars offer prescriptive guidance to practitioners in the form of instructional design theories (Reigeluth \& CarrChellman, 1999; Reigeluth, Beatty \& Myers, 2016), principles (Merrill, 2002; Silber, 2007) and models (Magliaro \& Shambaugh, 2006; Branch, 2010). In spite of all these conceptual tools, however, the designers themselves still have to make judgments in order to do their jobs (Smith \& Boling, 2009; Nelson \& Stolterman, 2012). At the minimum they have to select models, apply principles and adapt instructional theories, but in fact they exercise multiple forms of design judgments continuously as they work, and in every phase of their work (Gray et al., 2015). Little guidance is provided for these judgments (Smith \& Boling, 2009) and comparatively little attention is paid to design judgment as an object of direct study by scholars in the field (Boling \& Gray, 2014). Of 102 studies involving collection of data and focused on instructional design practice that were surveyed by Sugar in 2014, eight concerned decision-making and, of those, two focused on philosophies of instructional designers; one on their general philosophical beliefs (Sheehan \& Johnson, 2012) and one on teaching philosophies (Kanuka, Smith \& Kelland, 2013). The rest examine activities, collaboration, competencies and roles of designers. Furthermore, evidence shows repeatedly that designers in practice do not use the conceptual tools academics prescribe for their guidance (Rowland, 1992; Liu, Gibby, Quiros \& Demps, 2002; Christensen \& Osguthorpe, 2004; Visscher-Voerman \& 
Gustafson, 2004; Kenny, Zhang, Schwier \& Campbell, 2005; Ertmer, York, \& Gedik, 2009;).

Scholars who focus on design as the object of their study (many of them in architecture, product design and $\mathrm{HCI}$ ) portray it as a complex activity including distinctive modes of thought (Lawson, 2004; Lawson, 2006; Cross, 2011), difficult to capture in a single model (Lawson \& Dorst, 2009), and legitimately involving both the human character and the disciplined judgment of the designer (Nelson \& Stolterman, 2012). Design theory holds that studies of design practice are critical for creating tools that actually support designers (Stolterman, McAtee, Royer \& Thandapani, 2009), with the concurrent supposition that designers will not use tools mismatched to the actual practice of design. While much of the work in general design theory is carried out in fields of design other than instructional design, scholars within the field consider it applicable to their own work (Gibbons, 2013; Tracey \& Boling, 2014; Fortney \& Boling, 2017; Parrish \& Nelson, 2017; Boling \& Smith, 2017) as do the authors of this study.

This study furthers a research agenda that addresses the components of design theory and seeks to establish that instructional designers may be well served when scholars within the field understand more about how they actually do their work rather than developing tools for them without this understanding. Of the components to be investigated, core judgment — tacit beliefs regarding design, its role in the world and how it should be carried out - is important because it is considered fundamental to all design decisions (Nelson \& Stolterman, 2012), and because it has not yet been studied empirically among instructional designers. This form of judgement is part of the designer's character, not readily reflected upon because it forms something like the basic 
perspective of the designer rather than a propositional set of principles. With our heavy reliance on tools external to designers, can we show that practitioners in the field actually bring core judgments with them to the design enterprise? Can we begin to glimpse those core judgments or beliefs? The risk of not answering these questions, and many more regarding the actual (versus the hypothetical or imagined) practice of design, is that we will fail to understand fully how design actually operates; continue to see tools developed for instructional designers underutilized, with the waste of time and money that entails; miss opportunities for continual improvement in the education of our designers; and face difficulties in cross-disciplinary collaboration with professionals from game, interface, media, product and other fields of design.

\section{Instructional design and design judgment}

Smith and Boling demonstrated in 2009 that, in the conception of design conveyed through major textbooks and published definitions of the field, instructional designers are expected to choose appropriate instructional design models or theories for their current projects, or to adapt such models to fit their needs, but are not provided the guidance to do so. Efforts at providing such guidance, notably Reigeluth and CarrChellman (1999) instructional-design theories, still leave designers short of the point where a design has been realized, or even made concrete in its description. This is recognized explicitly in the discussion of the methods specified by these theories as probabilistic, meaning that their goal is "to attain the highest possible probability of desired results [but] do not guarantee ... desired instructional and learning outcomes"

(p.11). The specific probability that methods prescribed by theories will result in desired 
outcomes cannot be determined, however, because of the "formidable problem of empirically determining or validating all the probabilities for all the qualitatively different situations" in which they would be used, and the acknowledged interactions between multiple methods being used (p. 11). In other words, as they must do with instructional design models, instructional designers must choose and adapt methods, or combinations of methods - which are situational and which may each be carried out in multiple ways (p. 10) -- if they are to arrive at an appropriate design. Instructional-design theories do not, therefore, remove the problem of what Merrill, Drake, Lacy, Pratt and The ID2 Research Group characterized in 1996 as too much reliance on designers' judgment. Multiple efforts by scholars in the field to provide guidance to instructional designers may be observed (Merrill, 2002; Reigeluth \& Carr-Chellman, 1999; Silber, 2007; van Merriënboer, Clark, \& de Croock, 2002), as may be the points at which each of them still relies on designers' judgment.

It is surprising, therefore, to note the lack of scholarship in the field that addresses design judgment directly, rather than simply noting that it is a requirement for effective instructional design. One detailed theoretical treatment of how instructional designers exercise judgment (although this term is not used), is presented by Yanchar and Gabbitas (2011). They discuss the unexamined eclecticism (pragmatically using what works) or theoretical orthodoxy (using one single, rigidly applied method designing) that many designers fall back on when the tools of the field fail them (Rowland's study of designers). They argue that "eclectic" designers are actually using "conceptual design sense, [which] entails a designer's assumptions and values — often unarticulated and unexamined - about diverse aspects of the enterprise of instructional design" (p. 385) 
and recommend critical flexibility, a process whereby the designer engages in critical reflection to explicate their underlying assumptions and values. Other studies have also shown that instructional designers appear to refer to tacit philosophies in their design work (Rowland, 1992; Cox and Osguthorpe, 2003), but overall, efforts to describe these tacit philosophies have been minimal.

\section{Design judgment in design theory}

Dubberly (2005) dates the earliest design model he has identified to the 1920s, and his collection demonstrates that instructional design has no monopoly on design models. Close examination will also show that, as Bruce Archer (1965) makes explicit in the text accompanying his general design model,

When all has been said and done about defining design problems and analyzing design data, there still remains the real crux of the act of designing - the creative leap from pondering the question to finding a solution. ... there is no escape for the designer from the task of getting his own creative ideas. After all, if the solution to a problem arises automatically and inevitably from the interaction of the data, then the problem is not, by definition, a design problem. (p. 75)

That is, all models are dependent for their successful use on the human beings involved in the process of applying creativity as Archer puts it, or "throwing of a bridge across the chasm between problem and solution" as Cross (2007) (p. 439) argues, or exercising design judgment, the complex construct elaborated by Nelson and Stolterman (2012). 
In their comprehensive philosophy of design as a tradition of building and using knowledge, Nelson and Stolterman (2012) make a convincing case for a view of design in which the designer's character is considered integral and critical to designing. In this view, the professional character of a designer allows her to act as the integrating, synthesizing and acting instrument that structures and takes responsibility for designing, and the outcomes of design (Boling, 2008). The character of a designer includes a complex construct termed design judgment (Nelson and Stolterman, 2012) within which multiple forms of judgment are developed and exercised. Character and judgment are not viewed as innate, however, or as fixed. Holt (1997) states that "good judgment is an art ... art is defined as a human skill to be exercised ...it is something that can be developed in a purposive way" (p.123) bringing a "complex relativism" to bear on the complex task of design and the oftentimes ill structured, poorly defined tasks that designing requires (Rittel \& Webber, 1973).

Central to the construct of design character and design judgment is core judgment, described as the point at which "value and meaning are fixed ... in the sense that creating, modifying or rejecting [them] takes a great deal of effort" (Nelson and Stolterman, 2012; p. 200-201). Core judgments are not separate from the character of the designer, and are influenced only by inborn character and life experience, by creative action and its most meaningful consequences, and by experience of the sublime "— - an experience that moves us and transcends senses, feeling, and emotions" (p. 155). From these statements we infer that core judgments exercise a profound influence on all other forms of design judgment and of designers' actions, the more so because they are not formed, or exercised, intentionally. 
While the judgments required to adapt a design model or an instructional-design theory to one's current design situation may be accessible for discussion, justification and revision, design theory holds that those judgments are influenced by - in fact, bounded by -- core judgments. Instructional designers have been shown to exercise observable designerly judgments continuously in their practice (Gray et al., 2015); it is, therefore, important to begin asking about the core judgments they may hold.

Every individual may be assumed to hold a general set of core beliefs, but the research team was concerned in this study with core judgments in the context of designing. Given the lack of attention to this dimension of designing in the field's explanations of design (Smith and Boling, 2009), we did not feel we could assume that core judgments were in play for our participants. For this reason we began by asking whether these designers appeared to hold core judgments, although we expected that they would. More critically, we intended to describe the core judgments we might be able to infer in order to bring to light, and do so concretely, a dimension of designing that receives little attention in our field. Our research questions were, therefore:

1. Do instructional designers appear to hold core judgments as they discuss design artifacts (designed objects, experiences or systems)?

2. If so, what is the nature of core judgments that may be inferred from their discussion of design artifacts? 


\section{Method}

This is a multiple case study carried out from an interpretive phenomenological perspective. The research team adopted this perspective because core judgment is an interior phenomenon, and one requiring interpretation because it is not easily accessible to those experiencing it (Moran, 2000; Chapman \& Smith, 2002). The team elected to limit this study to description because the phenomenon of design judgment is not well recognized in the field of instructional design, either by scholars or by practitioners, and is therefore not ready to be treated in a causal or comparative mode of inquiry. In fact, while the design team expected, based on design literature, that instructional designers would be found to hold core judgments, it was not known whether these would be readily discernable or what their nature might be.

\section{Participants}

Participants for the study were recruited via listserv and social media posts. From the approximately 20 expressions of interest that we received, ten instructional design practitioners from three countries, each employed for a minimum of two years (average $=$ 11.2; range $=4-29)$ in the private sector were selected. The team considered that two years of experience was the minimum that would provide respondents with sufficient basis to identify and discuss designs largely from the viewpoint of practice versus that of their education. The team screened out respondents working inside public universities to avoid situations in which an individual might feel obliged to speak in the academic vocabulary of instructional design, or be careful to reflect ideas they might presume the team would expect to see. Although it was not a requirement, the individuals in the 
sample all held bachelors or masters level degrees, two in the field of instructional design and the rest in other areas of study (English, elementary education, economics, technology, computer science and microbiology). This is an exploratory study, so we appreciated the variety in our respondents but did not attempts to achieve a representative sample across the field of practice.

Table 1. Education, title and years experience of participants by pseudonym (instructional design" abbreviated to "ID" in this table for conservation of space)

\begin{tabular}{|c|c|}
\hline Participant & Key characteristics \\
\hline \multirow[t]{4}{*}{ Sharma } & BS in Biotechnology \\
\hline & MS in Industrial Microbiology \\
\hline & Does content/media development \\
\hline & 7 years of ID practice experience \\
\hline \multirow[t]{3}{*}{ Pearce } & Masters in Educational Psychology \\
\hline & Specialist Degree in IST \\
\hline & 20 years of ID practice experience, mainly in distance education \\
\hline \multirow[t]{3}{*}{ Halim } & BS in Computer Management \\
\hline & MS in Computer Science \\
\hline & 4 years of ID practice experience in for-profit educational settings \\
\hline \multirow[t]{4}{*}{ Gordon } & BA in Economics \\
\hline & In graduate school pursuing masters in linguistics \\
\hline & Have completed the "Ruth Clark certification" \\
\hline & 29 years of ID practice experience (since 1986) \\
\hline \multirow[t]{5}{*}{ Darmadi } & BA degree in Adult Education \\
\hline & Masters in Long-life Learning \\
\hline & Training Certificate focused on ADDIE \\
\hline & Learning Development Specialist and ID consulting \\
\hline & 5 years of ID practice experience \\
\hline \multirow[t]{5}{*}{ Mills } & BA in Broadcasting Television \& English \\
\hline & MA in English \\
\hline & Teacher for 5 years \\
\hline & Technical writer then ID job \\
\hline & 7 years of ID practice experience \\
\hline \multirow[t]{3}{*}{ Luis } & BA in chemistry \\
\hline & Master's in instructional design \\
\hline & 8 years of ID practice experience \\
\hline \multirow[t]{3}{*}{ Lopez } & BA and Masters in Elementary Education \\
\hline & "some certifications in ID" \\
\hline & 7 years of ID practice experience \\
\hline \multirow[t]{3}{*}{ Watson } & Bachelors in Technology Studies \\
\hline & Did media design part of the instructional design work \\
\hline & 7 of ID practice experience \\
\hline \multirow[t]{4}{*}{ Edwards } & Masters in ID 1997 \\
\hline & Currently working on her Phd \\
\hline & Worked on projects in UX interface design \\
\hline & 18 years of ID practice experience \\
\hline
\end{tabular}




\section{Instruments and Procedure}

A 60-minute, semi-structured interview was carried out with each participant via audio, followed by a short interview to ask clarifying questions and gather any additional thoughts participants had after about a week. These interviews were recorded via applications working in conjunction with $\mathrm{Skype}^{\mathrm{TM}}$ or with microcassette recorders; recordings were stored in the university's secure university digital document space. The main interview protocol included a short warm-up exchange asking the participant to recall any thoughts that came to mind regarding the main two questions which had been sent to participants in advance, then the primary questions, and brief concluding questions about job title, years of experience, types of design experience and education as shown in Figure 1. Our intention was not to arrive at any conclusions regarding the actual strengths or weaknesses of the artifacts described to us by participants. Those artifacts served as vehicles for discussion during which we anticipated the participants' statements would be informed by their core judgments and, further, that the concrete nature of their descriptions of the designs would provide data from which core judgments might be interpreted via phenomenological interpretive analysis (Chapman \& Smith, 2002).

\section{PRELIMINARY QUESTIONS}

- Think of an example of a design, not created by you but which you have used, that you consider to be a strong design. What makes you consider this a strong design?

- Think of an example of a design, not created by you but which you have used, that you consider to be a weak design. What makes you consider this a weak design?

Figure 1. Initial questions included in the email sent to participants, which also formed the basis for interviews. 
Prior to carrying out the interviews, team members watched several demonstration interviews, debriefing afterward. They practiced with each other, emphasizing reflective listening -- restating a respondent's main points and listening for adjustments and agreement. Then they each practiced interviewing individuals outside the research team and debriefed this experience as a group. This preparation emphasized comfort with prompting participants to elaborate on ideas stated, ensuring participants were understood and, for many on the team, building confidence for carrying out the interview in English.

\section{Data analysis}

Once the interviews were transcribed, each team member was paired with another one and this pair traded off listening to the other's interview before proceeding to a close reading of the transcript. The interviews and notes from them were then shared with the full research group and opened for interpretive discussion. Rounds of discussion focused on probable descriptions of how the participants perceive and make meaning of designtheir likely core judgments. These were not considered to be definitive descriptions, but to encompass possibilities that the group considers through intensive discussion to be possible. These discussions served as a means for the whole team to become well acquainted with the entire data corpus, and repeated discussions of ongoing analysis with the entire group served to help surface and set aside our personal core judgments, particularly when they conflicted with those of the participants. The team responded sometimes more positively, and sometimes less so, to the various judgments we interpreted from respondents' statements. However, our intention in this study was not to evaluate the core judgments we identified. We attempted to understand them as the 
respondents did and describe them so. The team did not assess inconsistent judgments as poor judgments

The team then conducted a form meaning field analysis, based in Carspecken (1996), yielding "a bounded set of possible meanings for the given communicative act [which] can be explored, not to determine the "true" meaning intended by the actor, but rather a paradigmatic set of meaning possibilities" (Gray, Toombs \& McKay, 2016, p. 4). The ability of the researchers to interpret meaning fields during an analysis of this kind depends either on immersion in the context of study (here, instructional design practice), or on sufficient prior experience to allow for well informed interpretations to be made. Members of the group included individuals holding project-intensive masters level degrees in the field of instructional design, individuals who have served internships of six months to a year working in the field as instructional designers. Individuals currently working as instructional designers and those who have worked previously as instructional designers and/or designers of instructional materials brought experience in commercial, government, higher education, K12 education and NGO domains to the analysis. Additional expertise in human-computer interface design and graphic design was represented.

Each team reviewed three to four transcripts and identified the statements with potential for relevant meanings, discussing these with the full group periodically. Analysis was guided by the conceptual question, "what judgment or belief might need to be in place for a designer to make these statements?" Segments of analysis were then reviewed by the primary investigator to move from a full set of meaning fields for each participant to a profile of the possible core judgments that individual had implied during 
their interviews. Table 2 shows the process as applied to one statement from one

interview.

Table 2. Sample of Analysis of a Single Interview Statement

Original So I, any project I undertake anymore, it starts with that. If I

Statement don't do a really good evaluation of what my audience is, what their capabilities are, what their

ability to understand the material...if I don't do that well, it's

just gonna fail. Like I said that was a horrible lesson to learn. I mean I suppose it was good in its own way, I don't make that kind of mistake anymore. But, to make the assumption that, because it's easy for you, that it's going to be easy for somebody else, isn't true. So that was the one that didn't work.

Restatement I didn't do a really good evaluation of what my audience is, (superficial - what their capabilities are, what their ability to understand the clarification) material. That's why the project was fail. That was a horrible lesson to learn. But I don't make that kind of mistake anymore.

\begin{tabular}{|c|c|c|}
\hline \multirow{2}{*}{$\begin{array}{l}\text { Meaning } \\
\text { Field }\end{array}$} & Foregrounded meanings & Underlying meanings \\
\hline & $\begin{array}{l}\text { I didn't do a really good } \\
\text { evaluation } \\
\text { AND } \\
\text { Knowing about my audience, } \\
\text { their capabilities, and their } \\
\text { ability to understand the } \\
\text { material are important. } \\
\text { AND } \\
\text { Without such understanding, } \\
\text { projects fail. } \\
\text { AND } \\
\text { That was a horrible lesson to } \\
\text { learn. } \\
\text { AND } \\
\text { But I don't make that kind of } \\
\text { mistake anymore. } \\
\text { AND } \\
\text { Because it is easy to make } \\
\text { wrong assumptions }\end{array}$ & $\begin{array}{l}\text { Good evaluations are } \\
\text { guarantors of success } \\
\text { AND } \\
\text { Good evaluations prevent } \\
\text { incorrect assumptions } \\
\text { AND } \\
\text { Design mistakes are process } \\
\text { mistakes } \\
\text { AND } \\
\text { Mistakes in design lead to } \\
\text { failure } \\
\text { AND } \\
\text { Design failure prevents } \\
\text { future mistakes } \\
\text { AND } \\
\text { Designers can expect to fail } \\
\text { if they do not follow process }\end{array}$ \\
\hline $\begin{array}{l}\text { Candidate } \\
\text { Core } \\
\text { Judgments }\end{array}$ & $\begin{array}{l}\text { Design is rational. } \\
\text { Design is process. } \\
\text { Process is deterministic. }\end{array}$ & \\
\hline
\end{tabular}




\section{Findings}

The result of our analysis describes the possible core judgments that could be inferred from the statements of each participant. It was possible to infer such judgments for every participant, which answers the first research question - these designers clearly do hold core design judgments. The inferences made by the research team with regard to the nature of those core judgments follow, summarized in Table 3 and narrative discussion of several selected participants follows.

Table 3. Inferred core judgments by participant (pseudonyms assigned by researchers)

\begin{tabular}{|c|c|}
\hline Participant & Inferred core judgments \\
\hline Sharma & $\begin{array}{l}\text { design is rational } \\
\text { the purpose of design originates with the designer } \\
\text { artifacts will behave as users and designers intend them to } \\
\text { less is more }\end{array}$ \\
\hline Pearce & $\begin{array}{l}\text { design is rational } \\
\text { design is responsive } \\
\text { the designer/user boundary is important in design } \\
\text { artifacts (the result of designing) are central to design } \\
\text { artifacts evoke anticipated results }\end{array}$ \\
\hline Halim & $\begin{array}{l}\text { design is rational } \\
\text { design is "in service to" } \\
\text { methods are valuable } \\
\text { designers control methods } \\
\text { design value resides in artifacts } \\
\text { artifacts create effects in the world }\end{array}$ \\
\hline Gordon & $\begin{array}{l}\text { design is rational } \\
\text { the focus of design is the artifact }\end{array}$ \\
\hline Darmadi & $\begin{array}{l}\text { design is rational } \\
\text { design is process } \\
\text { process is deterministic (of outcomes) } \\
\text { design knowledge is propositional }\end{array}$ \\
\hline Mills & $\begin{array}{l}\text { people all learn similarly } \\
\text { attention is core to human behavior/learning } \\
\text { propositional knowledge is central to design } \\
\text { artifacts are deterministic }\end{array}$ \\
\hline Luis & $\begin{array}{l}\text { design is rational } \\
\text { mechanisms of learning are well known } \\
\text { learning is individual } \\
\text { learning theories are guarantors of design } \\
\text { design is problem-solving } \\
\text { design is deterministic }\end{array}$ \\
\hline Lopez & $\begin{array}{l}\text { design is rational } \\
\text { the mechanisms of learning are known } \\
\text { artifacts are deterministic } \\
\text { principles constitute comprehensive support for designing }\end{array}$ \\
\hline Sanjeey & $\begin{array}{l}\text { design is rational } \\
\text { less is more } \\
\text { artifacts are the central object of designing } \\
\text { design is in service to, or design serves people } \\
\text { people's needs are known }\end{array}$ \\
\hline
\end{tabular}




\begin{tabular}{ll}
\hline Edwards & simplicity serves people's needs \\
& design is rational \\
& artifacts are not the central focus of design \\
design is deterministic & principles are generally sufficient to design \\
design is benevolent manipulation
\end{tabular}

The core judgments of several participants, selected for similarity and contrast that illuminate discussion are detailed below.

\section{Lopez.}

The potential core judgments of Lopez address learning, artifacts and principles. As such, they might be seen to represent an integrated tacit view of design strongly consistent with that apparently held by the field itself (Smith \& Boling, 2009). They include design is rational, the mechanisms of learning are known, artifacts are deterministic and principles constitute comprehensive support for designing. Altogether his core judgments reflect what may be called a fully rational view of design (Tripp, 1991; Stolterman, 2008) in which design is considered to be a form of problem solving, the dimensions of a problem are assumed to be knowable in advance of developing a solution, problem definitions do not change during the design process, and the match between a problem and a solution is made in propositional, that is, fully explicit terms. Further, and consistent with this view, Lopez views artifacts as deterministic (our term), meaning that the design of materials or experiences are seen as determining the responses people will have to them; no unforeseen alternative uses of designed materials or experiences are anticipated by designers. 


\section{Sanjeey.}

Repeated statements made by Sanjeey convey a strong adherence to the wellknown design philosophy that less is more, a philosophical position associated with minimalist design (Savvi, 1989). This core judgment implies another, which is that artifacts are the central object of designing. At the same time this designer appears to hold the judgment that design is in service to, or design serves people, a position inconsistent with core values of minimalist design which suffered a large scale, public failure through focusing on artifacts to the exclusion of people's needs and desires (Holston, 1989). Taken together with people's needs are known and simplicity serves people's needs, however, we see the possibility that this designer's view of service is also rational and consistent with the judgment design is rational.

\section{Sharma.}

Sharma's possible core judgments are for the most part internally consistent, with design is rational seeming to be central. This designer expresses the implicit rationality of design in many ways, including emphasis on analysis, systematic design, a cognitive approach to design, and efficiency in design as well as in artifacts. Related to rationality are the core judgments that the purpose of design originates with the designer, and that artifacts will behave as users and designers intend them to. Artifacts are further seen to embody the designer's purpose, meaning that design decisions are taken with the expectation that the reason for them will be conveyed, and conveyed through the artifact. Sharma also appears to hold the core judgment less is more. In the light of the other core judgments interpreted from this designer, less is more seems to be an extension of design is rational. Expressions indicating this judgment center on efficiency of design, on the 
notion that clarity created through simplicity will be perceived as clarity by a learner and that concise design is assumed to be clear design.

\section{Edwards.}

For Edwards the core judgment artifacts are not the central focus of design is interpreted from a notable lack of statements referencing artifacts. A related group of judgments, design is rational, design is deterministic and principles are generally sufficient to design, can be seen as consistent with each other and with the lack of attention paid to artifacts. An additional core judgment interpreted from this designer's statements is that design is benevolent manipulation - attention to users' needs, work habits and comfort are paired with requiring user activities and designing to make learners accept knowledge.

\section{Clustering core judgments}

For individual designers, core judgments often cluster together in a way that feels expected. Design is rational and design is deterministic seem as though they express a consistently scientific view of designing. Less is more and design should be flexible and adaptable likewise seem to express core judgments consistent with each other, and with what might be termed a "least harm" view of designing. If core judgments include fundamental orientations that extend beyond design, permeating the lives and actions of the designers who hold them, we would expect this to be the case.

However, core judgments are not inevitably clustered together in outwardly logical ways. They may be consistent with that designer's character, represent core judgments not strongly integrated via experience, or simply signal that our study method did not provide for a full expression of that designer's beliefs. Pearce's case illustrates 
this; design is discussed in such a way as to suggest the core judgments designer/user boundary is important in design, design is responsive and artifacts evoke anticipated results. While these judgments are not fully irreconcilable, they are not smoothly interlocking either. The first two suggest this designer's view of design's place in the world lying between designer and user and adjusting in response to the user. Coupling these with the judgment artifacts evoke anticipated results could suggest that this designer views human beings as invariant in their behavior, meaning that responding to a defined human need via design is expected to result in a known response in return. It might imply that the designer views design itself as capable of constraining responses from users to only those anticipated in advance. Or it could mean that the designer holds imperfectly reconciled judgments that have not as yet risen to consciousness and therefore resolved.

\section{Discussion}

While the finding that instructional designers do hold core judgments may seem too obvious to discuss, it bears a little examination here. With the exception of Yanchar and Gabbitas (2011), a presumption of conscious intentionality is assumed in the language most often used to describe instructional design. But, while this study was not evaluative, it may be clear that some of the core judgments interpreted here are consistent with some explicit views of design in the field and inconsistent with others. In fact, the view that design is rational and the view that design is pervasively impacted by core judgments, which are by definition not rational (Nelson \& Stolterman, 2012), are distinctly incompatible. (Note that although most of these designers hold the core judgment that design is rational, we are making the point that core judgments are not themselves 
rational; they are tacit beliefs.) Therefore, simply acknowledging that practicing instructional designers hold core judgments begs the question of the role of philosophy in our practice. If our tools and models are developed on the presumption either that designers' core judgments are irrelevant (because they are not recognized to exist), the risk is that those tools may not be accepted or used by designers, or that their benefits may be limited through unconscious conflicts with those core judgments.

Many of the core judgments inferred from our discussions with practicing instructional designers echoed explicit perspectives familiar to academic instructional designers, like design is rational and design is deterministic. It was tempting, given our collective educational experience, to assume that education in the field instilled these beliefs in the participants but we are not able to do so. The educational experiences of the participants varied, and we did not collect sufficient detail about them to establish a nonobvious commonality between them. We would also expect some interplay between innate character, life experience, design experience and moments of profound impact as theorized by Nelson \& Stolterman (2012) to form and affect core judgments. It may be that individuals are drawn to, or remain in, design communities where frequently espoused values are consonant with their own deeply held views. It may also be that early learning experiences, or profound ones, shift core judgments in the direction of the perspectives held by educators in various domains of design. For experienced designers, it is also possible that their own practice (including practice with peer designers and as members of design teams), and the outcomes of that practice, have influenced their core judgments. We are also unable to claim, based on the small number of participants, that 
most, or even many, instructional designers hold core judgments consistent with those presumed by the scholars who develop tools for them.

\section{Implications}

From the perspective of design studies in the field, this glimpse of the core judgments held by practicing instructional designers demonstrates the applicability of design theory into exactly how design is accomplished in the gap between models or theories and action. Development of tools by scholars - instructional theories and strategies, conceptual and process models, principles and guidelines — should, for example, take into account the fact that use of these tools is influenced by the core judgments of individuals. Those judgments, or beliefs about design, cannot be taken for granted and our tools should, perhaps, seek to leverage them as an irrational contributor to disciplined design rather than replace them with prescriptive guidance.

With more comprehensive understanding of design practice and how its tacit, as well as its visible and explicit dimensions, function, design educators can begin to consider how core judgments can be developed and shaped. What aspects of the curriculum and of educational experiences should be emphasized to acknowledge core judgments and encourage reflection on them? Can propositional methods address this aspect of designer development (Boling \& Merrill, 2017)?

Practicing instructional designers, and those who teach and train instructional designers, can review the core judgments found in this study and reflect on their own. Are the decisions they make daily during practice consistent with these judgments? A designer who holds the core judgment that design is in service to, but recognizes she is making decisions in an effort to create a "perfect" or polished artifact — that is, focusing 
on the artifact to the detriment of its user-can consider explicitly whether she wants to work on adjusting her core judgments, or adjusting the kinds of decisions she is making. This designer will improve her practice through such targeted reflection (Schön, 1984).

\section{Limitations of the study}

This is a small scale study and, without knowing in advance what to expect from a stratified or even a comprehensive sample of instructional designers, the team recruited from likely sources of respondents, accepting those who reported having several years of experience. We did not screen for their educational backgrounds or the context of their practice, except for excluding those practicing in higher education. Therefore, we are not able to comment in any way on the possible influence their personal characteristics, education, or experiences in general may have had on the core judgments we inferred that they hold.

We did not watch the participants working and did not ask them about their own design decisions. Knowing that studies in our field have sometimes taken an evaluative stance toward practicing designers, and concerned that the suggestion of such a stance might prompt some participants to constrain their discussion, we elected to ask them instead about designs they had used but not designed themselves.

\section{Future Research}

We saw a general orientation toward design as a predominately rational enterprise, which is only one of multiple, viable orientations toward design (Nelson \& Stolterman, 2012; Parrish \& Nelson, 2017), but we interpreted these core judgments in individuals with different educational backgrounds. We cannot assume therefore either that 
instructional design attracts individuals holding these core judgments, or that the field demands such judgments from instructional designers. Future studies need to focus on what factors affect the formation of such judgments among ID practitioners. What role do ID education, culture of the field, and the practitioner's own precedent knowledge play in shaping ID core judgments? This study, others that have focused on design practice, and those yet to be conducted, are necessary steps toward considering how design may be accomplished as disciplined, rigorous thoughts and actions under the control of designers for whom models and theories are viewed as tools which are subordinate to designers and their judgments.

\section{Acknowledgments}

Two team members involved in interviews and part of the analysis who were not involved in writing this manuscript will be acknowledge by name. 


\section{References}

Archer, B. (1965). Systematic method for designers. London: The Design Council.

Boling, E. (2008). From students to scholars: Revision of the doctoral program in Instructional Systems Technology at Indiana University. In, M. Orey, J. McLendon \& R. Branch (Eds.), Educational media and technology yearbook 2008. (pp. 31-40) Westport, CT: Libraries Unlimited.

Boling, E. \& Gray, C.M. (2014). Design: The topic that should not be closed. TechTrends, 38(6); 17-19.

Boling, E. \& Merill, D. (2017). Teaching the complex performance of instructional design: Why we cannot use the (existing) tool of instructional design; Response and rejoinder. In A. Carr-Chelman \& G. Rowland (Eds.). Issues in technology, learning, and instructional design. (pp. 81-87). New York, NY: Routledge.

Boling, E. \& Smith, K. M. (2017). Changing conceptions of design. In Reiser, R. \& Dempsey, J. (Eds.). Trends and Issues in Instructional Design and Technology. (pp. 323-330). New York, NY: Pearson.

Branch, R. M. (2010). Instructional design: The ADDIE Approach. New York, NY: Springer.

Carspecken, P. F. (1996). Critical ethnography in educational research: A theoretical and practical guide. New York, NY; London, England: Psychology Press.

Chapman, E. \& Smith, J. A. (2002). Interpretative phenomenological analysis and the new genetics. Journal of Health Psychology, 7(2), 125-130. 
Christensen, T. K. \& Osguthorpe, R. T. (2004). How do instructional-design practitioners make instructional-strategy decisions? Performance Improvement Quarterly, 17(3): 45-65.

Cox, S., \& Osguthorpe, R. T. (2003). How do instructional design professionals spend their time? TechTrends, 47(3), 45-47. doi:10.1007/BF02763476

Cross, N. (2007). Designerly ways of knowing. London: Springer-Verlag.

Cross, N. (2011). Design thinking: How designers think and work. Oxford, NY: Bloomsbury Academic.

Dubberly, H. (2005). How do you design? A compendium of models. Retrieved from http://www.dubberly.com/articles/how-do-youdesign.html

Ertmer, P. A., York, C. S., \& Gedik, N. (2009). Learning from the pros: How experienced designers translate instructional design models into practice. Educational Technology, 49(1): 19-27.

Fortney, K. \& Boling, E. (2017). Developing design expertise; Response and rejoinder. In A. Carr-Chelman \& G. Rowland (Eds.). Issues in technology, learning, and instructional design. (pp. 57-63). New York, NY: Routledge.

Gibbons, A. S. (2013). An architectural approach to instructional design. New York, NY: Routledge.

Gray, C. M., Dagli, C., Demiral-Uzan, M., Ergulec, F., Tan, V., Altuwaijri, A. A., ... \& Boling, E. (2015). Judgment and instructional design: How ID practitioners work in practice. Performance Improvement Quarterly, 28(3), 25-49. doi:10.1002/piq. 21198 
Gray, C. M., Toombs, A. L. \& McKay, C. (2016, May). Meaning reconstruction as an approach to analyze critical dimensions of HCI research. In Proceedings of the 2016 CHI Conference Extended Abstracts on Human Factors in Computing Systems (pp. 328-340). doi:10.1145/2851581.2892571

Holt, J. E. (1997). The designer's judgement. Design Studies, 18(1),113123. doi:10.1016/S0142-694X(96)00013-0

Holston, J. (1989). The modernist city: An anthropological critique of Brasilia. Chicago, IL: University of Chicago Press.

Januszewski, A., \& Molenda, M. (Eds.). (2013). Educational technology: A definition with commentary. New York, NY; London, England: Routledge.

Kanuka, H., Smith, E. E., \& Kelland, J. H. (2013). An inquiry into educational technologists' conceptions of their philosophies of teaching and technology. Canadian Journal of Learning and Technology, 39(2), 1-27.

Kenny, R. F., Zhang, Z., Schwier, R. A. \& Campbell, K. (2005). A review of what instructional designers do: Questions answered and questions not answered. Canadian Journal of Learning and Technology, 31(1):9-26. Retrieved from http://www.cjlt.ca/content/vol31.1/kenny.html

Lawson, B. (2004). Schemata, gambits and precedent: some factors in design expertise. Design studies, 25(5), 443-457. doi:10.1016/j.destud.2004.05.001

Lawson, B. (2006). How designers think: the design process demystified. . New York, NY: Routledge.

Lawson, B., \& Dorst, K. (2009). Design expertise. 2009. New York, NY: Routledge. 
Liu, M., Gibby, S., Quiros, O. \& Demps, E. (2002). Challenges of being an instructional designer for new media development: A view from the practitioners. Journal of Educational Multimedia and Hypermedia, 11(3): 195-219.

Magliaro, S. \& Shambaugh, N. (2006). Student models of instructional design. Educational Technology Research and Development, 54(1): 83-106.

Merrill, D., Drake, L., Lacy, M., Pratt, J. \& The ID2 Research Group. (1996). Reclaiming instructional design. Educational Technology, 36(5), 5-7.

Merrill, D. (2002). A Pebble-in-the-Pond Model for instructional design. Performance Improvement, 41(7), pp. 41-46. doi:10.1002/pfi.4140410709

Moran, D. (2000). The phenomenology reader. New York, NY: Psychology Press.

Nelson, H. G. \& Stolterman, E. (2012). The design way: Intentional change in an unpredictable world (2nd ed.). Cambridge, MA; London, England: MIT Press.

Parrish, P. \& Nelson, H. (2017). Instructional design as design; Response and rejoinder. In A. Carr-Chellman \& G. Rowland (eds.). Issues in technology, learning and instructional design. (pp. 7-11). New York, NY: Routledge.

Reigeluth, C. M. \& Carr-Chellman, A. (1999). Instructional-design theories and models (volume II): A new paradigm of instructional theory. New York, NY: Lawrence Erlbaum.

Reigeluth, C. M., Beatty, B. \& Myers, R. (2016). Instructional-design theories and models, Volume IV: The learner-centered paradigm of education. New York, NY: Routledge.

Rittel, H. \& Webber, M. (1973). Dilemmas in a general theory of planning. Policy Sciences, 4(2), 155-169. doi:10.1007/BF01405730 
Rowland, G. (1992). What do instructional designers actually do? An initial investigation of expert practice. Performance Improvement Quarterly, 5(2), 65-86. doi:10.1111/j.1937-8327.1992.tb00546.x

Savvi, V. (1989). Less is more. Barcelona, Spain: Actar.

Schön, D. (1984). The reflective practitioner: How professionals think in action. New York, NY: Basic Books.

Sheehan, M. D., \& Johnson, R. B. (2012). Philosophical and methodological beliefs of instructional design faculty and professionals. Educational Technology Research and Development, 60(1), 131-153.

Silber, K. H. (2007). A principle-based model of instructional design: A new way of thinking about and teaching ID. Educational Technology, 47(5), 5-19.

Smith, K. M. \& Boling, E. (2009). What do we make of design? Design as a concept in educational technology. EducationalTechnology, 49(4), 3-17.

Stolterman, E. (2008). The nature of design practice and implications for interaction design research. International Journal of Design, 2(1), 55-65.

Stolterman, E., McAtee, J., Royer, D. \& Thandapani, S. (2009, July). Designerly tools. In D. Durling, C. Rust, L. Chen, P. Ashton \& K. Friedman (eds.). Undisciplined! Design Research Society Conference 2008. Sheffield, UK. Retrieved from http://shura.shu.ac.uk/491/

Sugar, W. (2014). Studies of ID practices: A review and synthesis of research on current ID practices. New York, NY: Springer. 
Tracey, M. \& Boling, E. (2014). Preparing instructional designers: Traditional and emerging perspectives. In Specter, M., Merrill, D., Elan, J. \& Bishop, M. J. (Eds.). (pp. 653-660). Handbook of Research on Educational Communications and Technology. (pp. 653-660). Ney York, NY: Springer.

Tripp, S. D. (1991, February).Two theories of design and instructional design. Paper presented at the Annual Meeting of AECT, Orlando, FL.

van Merriënboer, J. J. G., Clark, R. E. \& de Croock, M. B. M. (2002). Blueprints for complex learning: The 4C/ID-model. Educational Technology, Research and Development, 50(2); 39-64. doi:0.1007/BF02504993

Visscher-Voerman, I. \& Gustafson, K. L. (2004). Paradigms in the theory and practice of education and training design. Educational Technology Research and Development, 52(2), 69-89. doi:10.1007/BF02504840

Yanchar, S. C. \& Gabbitas, B. W. (2011). Between eclecticism and orthodoxy in instructional design. Educational Technology Research and Development, 59(3), 383-398. doi:10.1007/s11423-010-9180-3 